\title{
Effect of pH on Hydrogen Absorption into Steel in Neutral and Alkaline Solutions
}

\author{
Norihiro Fujimoto ${ }^{1, *}$, Takashi Sawada $^{1}$, Eiji Tada $^{2}$ and Atsushi Nishikata ${ }^{2}$ \\ ${ }^{1}$ NTT Device Technology Labs, NTT Corporation, Atsugi 243-0198, Japan \\ ${ }^{2}$ Depatment of Materials Science and Engineering, Tokyo Institute of Technology, Tokyo 152-8552, Japan
}

The corrosion behavior and the amount of absorbed hydrogen in steel were investigated in neutral and alkaline solutions with pH values ranging from 8.3 to 12.4. The amount of absorbed hydrogen into steel during immersion in the solutions was evaluated by thermal desorption analysis. In the alkaline solution of $\mathrm{pH}$ 12.4, the steel maintained a noble potential in a passive state, and almost no hydrogen absorption into the steel was detected. However, as the $\mathrm{pH}$ moved towards a more neutral $\mathrm{pH}$, the corrosion potential shifted in the less noble direction, and the amount of hydrogen absorbed increased dramatically. These results indicate that the steel surface became more active in the neutral solutions, and the hydrogen evolution reaction, one of the cathodic reactions of steel corrosion, was enhanced close to the neutral $\mathrm{pH}$ with decreasing corrosion potential in the less noble direction. The change of the surface state from passive to active with decreasing pH accelerated the anodic dissolution of steel and made the corrosion potential less noble, resulting in the enhancement of hydrogen evolution and absorption reactions on the steel. [doi:10.2320/matertrans.M2016360]

(Received October 12, 2016; Accepted November 29, 2016; Published January 25, 2017)

Keywords: high-strength steel, thermal desorption analysis, corrosion potential, hydrogen embrittlement, carbonation, pre-stressed concrete, pore water

\section{Introduction}

Pre-stressed concrete (PC) is a structural material with high strength and resiliency to both tensile and compressive stresses. It has therefore been used for poles, slabs, and beams in a range of infrastructure applications. To introduce compressive stress to concrete structures, pre-stretched highstrength steels are often embedded in concrete slurry. In addition to strengthening of $\mathrm{PC}$, formation of cracks is mitigated due to compressive stress in concrete structures. These advantages elongate the lifetimes of concrete structures in usage environments.

However, over many years, cracks form in PC by aging degradation of the concrete. One aging degradation mechanism in concrete structures is carbonation, where carbon dioxide in the atmosphere reacts with calcium in concrete, resulting in a lower $\mathrm{pH}$, i.e., neutralization ${ }^{1,2)}$. After the formation of cracks, uptake of waters containing corrosive agents occurs; these waters reach the surface of the pre-stressed steels in the PC. Normally, steels in concrete structures are in a passive state due to the formation of a passive film in high-alkaline concrete environments ${ }^{3)}$. However, aging degradation of concrete changes the solution chemistry of the pore water in cracks in concrete structures due to carbonation and uptake of $\mathrm{Cl}$ ions, resulting in a lower water $\mathrm{pH}$ and depassivation of steel. Therefore, steel corrosion occurs depending on the extent of aging.

In an aqueous environment, hydrogen atoms can evolve through a cathodic reduction reaction, as described by eqs. (1) and (2), depending on the $\mathrm{pH}$ of the environment. These reduction reactions are one of a number of cathodic reactions that occur during metallic corrosion. The evolved hydrogen atoms are adsorbed onto the surface of metallic materials through the reaction shown in eq. (3). Then some amount of the adsorbed hydrogen is absorbed into metallic materials through hydrogen adsorption processes ${ }^{4,5)}$ :

*Corresponding author, E-mail: fujimoto.norihiro@lab.ntt.co.jp

$$
\begin{gathered}
\mathrm{H}^{+}+\mathrm{e}^{-} \rightarrow \mathrm{H}_{\mathrm{ad}} \\
\mathrm{H}_{2} \mathrm{O}+\mathrm{e}^{-} \rightarrow \mathrm{H}_{\mathrm{ad}}+\mathrm{OH}^{-} \\
\mathrm{M}+\mathrm{H}_{\mathrm{ad}} \rightarrow \mathrm{M}-\mathrm{H}_{\mathrm{ad}}
\end{gathered}
$$

Generally, during metallic corrosion in acidic media, the evolution reaction of hydrogen atoms is the main cathodic reaction on less noble metals such as iron. In contrast, in neutral and alkaline solutions, the evolution reaction of hydrogen atoms on metallic materials is less significant because the proton concentration is quite low. However, the hydrogen evolution reaction can occur during metallic corrosion in solutions at relatively high $\mathrm{pH}$ depending on the corrosion potential. If the corrosion potential is less noble than the equilibrium electrode potential of the hydrogen evolution reaction at the $\mathrm{pH}$ of the solution, the hydrogen evolution reaction takes place thermodynamically, resulting in the formation of adsorbed hydrogen atoms. Furthermore, some of the adsorbed hydrogen atoms are absorbed into metallic materials. The absorption of hydrogen atoms has been experimentally confirmed during steel corrosion in weak acid and neutral media ${ }^{6}$. On the other hand, according to the study by Hara et al., almost no hydrogen atoms are absorbed into steel in alkaline solutions ${ }^{7)}$; this implies that hydrogen embrittlement of steel does not occur in high-alkaline environments, such as fresh concrete pore water.

However, according to some reports, cracking or failure of steels in concrete structures occurs even in alkaline environments ${ }^{8,9)}$, where cracking or failure is thought to be associated with hydrogen embrittlement of steels. Hydrogen embrittlement is one environmental deterioration phenomenon in which metals and alloys suddenly break down due to absorption of hydrogen atoms under applied tensile stress. In addition, high-strength steels used in PC to apply high compressive stress to concrete structures have a relatively higher susceptibility to hydrogen embrittlement due to their high strength. Therefore, to investigate the potential for hydrogen 
embrittlement in aging concretes, the hydrogen absorption behavior of steels should be studied in neutral and weak alkaline solutions. However, the mechanism and quantity of hydrogen absorption into steels in neutral and weak alkaline solutions have not been reported and are not yet fully understood.

In this study, hydrogen absorption into steels in neutral and weak alkaline solutions simulating pore water in aging concretes is investigated. In addition, the possibility of environmental degradation of steels in neutral and weak alkaline solutions is discussed based on the corrosion behavior and the amount of absorbed hydrogen.

\section{Experimental Procedure}

\subsection{Samples}

The material used in this study was a 1420-MPa-class high-strength steel bar with a diameter of $9 \mathrm{~mm}$. The chemical composition of the steel bar is shown in Table 1 . The surface of the as-received steel bar was machined to remove surface scales (black skin) formed during the steelmaking process. The steel bar was sliced into small disks with a thickness of about $3 \mathrm{~mm}$. The surface of the steel disks was ground successively with $\mathrm{SiC}$ paper down to a Japan Industrial Standard (JIS) \#800 grit. Finally, the steel disks were rinsed ultrasonically in acetone and used as samples for electrochemical and corrosion tests.

\subsection{Test solutions}

A series of test solutions, listed in Table 2, were prepared with reagent grade chemicals (Kanto Chemical Co., Inc., Japan) and deionized water. The $\mathrm{pH}$ of the test solutions was adjusted from 8.3 to 12.4 to simulate the $\mathrm{pH}$ of pore waters corresponding to the extent of neutralization in aging concretes. One test solution was an alkaline solution of $50 \mathrm{~mol} /$ $\mathrm{m}^{3} \mathrm{NaOH}$ at $\mathrm{pH} 12.4$, to simulate pore water in fresh concrete. The other test solutions were prepared across a $\mathrm{pH}$ range from 8.3 to 11.1 by adding $\mathrm{Na}_{2} \mathrm{CO}_{3}$ and $\mathrm{NaHCO}_{3}$ to an $\mathrm{NaOH}$ solution, while maintaining the total carbonate concentration at $50 \mathrm{~mol} / \mathrm{m}^{3}$. All test solutions also contained $1 \mathrm{kmol} / \mathrm{m}^{3} \mathrm{Na}_{2} \mathrm{SO}_{4}$ as a supporting electrolyte.

Table 1 Chemical composition of the steel bar (mass\%).

\begin{tabular}{cccccc}
\hline $\mathrm{C}$ & $\mathrm{Si}$ & $\mathrm{Mn}$ & $\mathrm{S}$ & $\mathrm{P}$ & $\mathrm{Fe}$ \\
\hline 0.34 & 0.27 & 0.78 & 0.006 & 0.017 & Balance \\
\hline
\end{tabular}

Table 2 A series of test solutions and their $\mathrm{pH}$ values.

\begin{tabular}{lrr}
\hline No. & \multicolumn{1}{c}{ Test solution } & pH \\
\hline 1 & $50 \mathrm{~mol} / \mathrm{m}^{3} \mathrm{NaOH}+1 \mathrm{kmol} / \mathrm{m}^{3} \mathrm{Na}_{2} \mathrm{SO}_{4}$ & 12.4 \\
\hline 2 & $50 \mathrm{~mol} / \mathrm{m}^{3} \mathrm{Na}_{2} \mathrm{CO}_{3}+1 \mathrm{kmol} / \mathrm{m}^{3} \mathrm{Na}_{2} \mathrm{SO}_{4}$ & 11.1 \\
\hline 3 & $25 \mathrm{~mol} / \mathrm{m}^{3} \mathrm{NaHCO}_{3}+25 \mathrm{~mol} / \mathrm{m}^{3} \mathrm{Na}_{2} \mathrm{CO}_{3}+1 \mathrm{kmol} / \mathrm{m}^{3} \mathrm{Na}_{2} \mathrm{SO}_{4}$ & 9.8 \\
\hline 4 & $45 \mathrm{~mol} / \mathrm{m}^{3} \mathrm{NaHCO}_{3}+5 \mathrm{~mol} / \mathrm{m}^{3} \mathrm{Na}_{2} \mathrm{CO}_{3}+1 \mathrm{kmol} / \mathrm{m}^{3} \mathrm{Na}_{2} \mathrm{SO}_{4}$ & 9.3 \\
\hline 5 & $50 \mathrm{~mol} / \mathrm{m}^{3} \mathrm{NaHCO}_{3}+1 \mathrm{kmol} / \mathrm{m}^{3} \mathrm{Na}_{2} \mathrm{SO}_{4}$ & 8.3 \\
\hline
\end{tabular}

\subsection{Test procedure}

\subsubsection{Immersion and electrochemical tests}

Immersion and electrochemical polarization tests were undertaken in a conventional three-electrode cell with an HZ5000 potentio/galvanostat (Hokuto Denko Corp., Japan) to investigate the corrosion behaviors of the steel disks in the test solutions. One steel disk sample served as the working electrode for each test. A silver/silver chloride electrode (SSE) in saturated $\mathrm{KCl}$ and a platinum sheet were used as the reference electrode and the counter electrode, respectively.

In the immersion tests, the corrosion potential of the steel disks was monitored for $24 \mathrm{~h}$ in the test solutions. For measurement of dynamic polarization curves, the steel disks were polarized from a corrosion potential in the anodic or cathodic direction at a scan rate of $0.5 \mathrm{mV} / \mathrm{s}$. These measurements were undertaken at an ambient temperature of about $25^{\circ} \mathrm{C}$.

\subsubsection{Surface analysis}

The surface of the steel disks after the immersion tests was observed with a JSM-6010LA scanning electron microscope (JEOL Ltd., Japan). Corrosion products formed on the steel disks during the immersion tests were analyzed with a MiniFlex600 X-ray diffractometer (Rigaku Co., Ltd, Japan). X-ray diffraction measurements were undertaken using the $\theta-2 \theta$ method at $40 \mathrm{kV}$ and $15 \mathrm{~mA}$ with a wavelength of $0.15418 \mathrm{~nm}$ $(\mathrm{Cu}-\mathrm{K} \alpha)$.

\subsubsection{Thermal desorption analysis}

Hydrogen desorption rates from steel disks after 72-h immersion in the test solutions were measured by thermal desorption analysis (TDA) with a TDS1200 (ESCO Co., Ltd., Japan). The steel disks (diameter: $9 \mathrm{~mm}$; thickness: $3 \mathrm{~mm}$ ) were used as samples. The TDA measurements were undertaken within $30 \mathrm{~min}$ of immersion test completion to minimize the release of absorbed hydrogen from the steel disks at room temperature. After the immersion tests, the steel disks were set in a vacuum chamber at a pressure of the order of $10^{-7} \mathrm{~Pa}$ and heated from room temperature to $500^{\circ} \mathrm{C}$ at a constant heating rate of $200^{\circ} \mathrm{C} / \mathrm{h}$. The TDA spectrum for the steel disks without the immersion test was also obtained as a reference.

\section{Results}

\subsection{Influence of $\mathrm{pH}$ on the corrosion behavior of steel}

Figure 1 shows changes in the corrosion potential of steel disks during 24-h immersion in test solutions over a range of $\mathrm{pH}$ values. In each test solution, the corrosion potential decreased rapidly in the less noble direction just after immersion, and then reached an almost constant value. It can also be seen from Fig. 1 that the corrosion potential becomes less noble in solutions with decreasing $\mathrm{pH}$.

The corrosion potential after 24-h immersion is plotted as a function of $\mathrm{pH}$ in Fig. 2. In the higher $\mathrm{pH}$ region above 9.8, the corrosion potential increased with $\mathrm{pH}$ (slope: $55 \mathrm{mV} /$ $\mathrm{pH})$. In contrast, in the $\mathrm{pH}$ region below 9.8, the corrosion potential changed significantly, by more than $200 \mathrm{mV}$, in the less noble direction. The corrosion potential did not change significantly in the $\mathrm{pH}$ region below 9.3, regardless of the $\mathrm{pH}$ value.

Figure 3 shows SEM images for the surfaces of the steel disks after the 24-h immersion tests; steel surfaces exposed to 


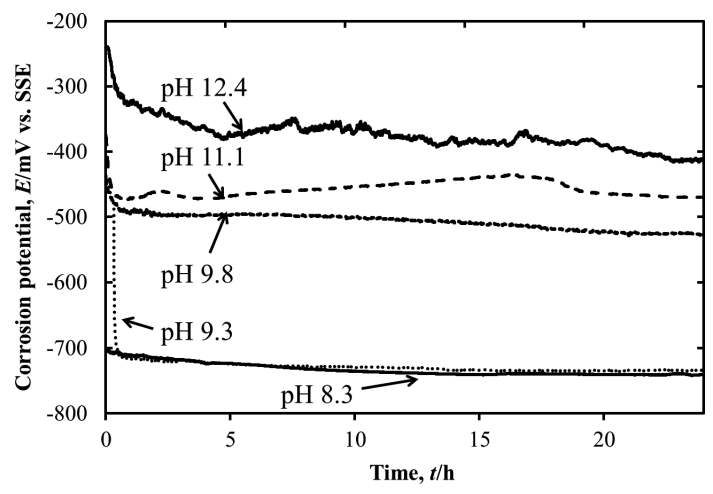

Fig. 1 Changes in the corrosion potential of steel disks during 24-h immersion in test solutions over a range of $\mathrm{pH}$ values.

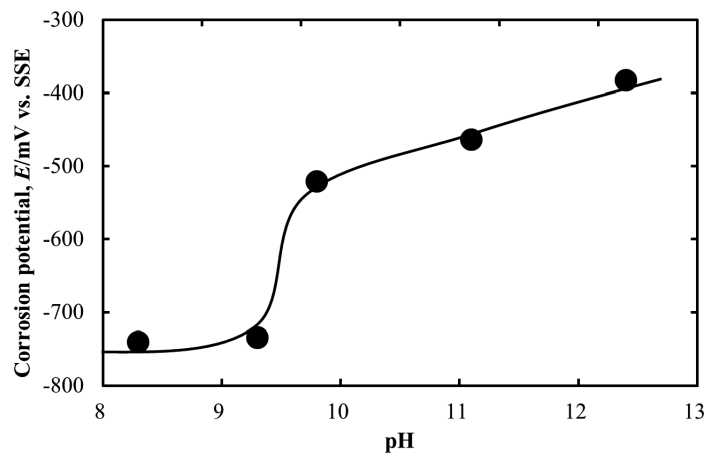

Fig. 2 Change in corrosion potential for the steel disks after 24-h immersion tests as a function of solution $\mathrm{pH}$

a pH higher than 11.1 retained a metallic luster slightly, although at $\mathrm{pH} 11.1$ some iron corrosion products were observed on the steel surface. In contrast, the surfaces of the steel disks exposed to a $\mathrm{pH}$ lower than 9.8 were obviously covered in iron corrosion products, and the amount of the corrosion products increased with decreasing $\mathrm{pH}$ (Fig. 3). Further, as shown in Fig. 4, FeOOH and/or $\mathrm{Fe}_{2} \mathrm{O}_{3}$ were detected by X-ray diffraction measurements on steel after immersion in the solutions with a $\mathrm{pH}$ less than 9.8. These results indicate that the steel surface is in a passive state in the $\mathrm{pH} 12.4$ solution, but that the passive state cannot be maintained after immersion in a solution lower than $\mathrm{pH} 9.8$.

\subsection{Influence of $\mathbf{p H}$ on corrosion reaction of steel}

For further investigation of the corrosion behavior, anodic and cathodic polarization curves for steel disks were measured in the test solutions with various $\mathrm{pH}$ values. Figures 5 and 6 show the anodic and cathodic polarization curves for the steel disks, respectively. The anodic polarization curves shifted in the anodic direction with increasing $\mathrm{pH}$, as shown in Fig. 5. Furthermore, the anodic current densities also decreased sharply at $\mathrm{pH}$ between 9.3 and 9.8 . In the test solution at $\mathrm{pH} 12.4$, passive behavior was clearly visible around the corrosion potential. These anodic polarization behaviors at various $\mathrm{pH}$ values are in good agreement with the surface observations and XRD results shown in Figs. 3 and 4.

The cathodic polarization behaviors of the steel disks in the test solutions also depended on $\mathrm{pH}$, as shown in Fig. 6. In the case of a $\mathrm{pH}$ higher than 9.8, a diffusion-limiting current den-

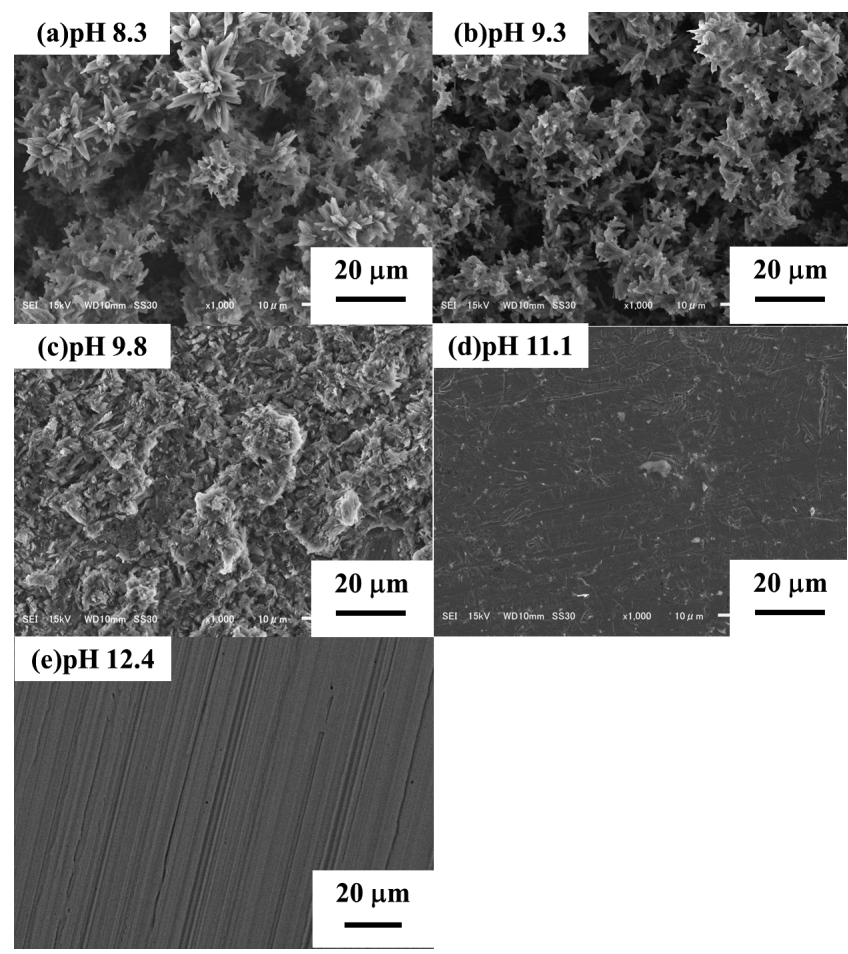

Fig. 3 SEM images for the surfaces of the steel disks after the 24-h immersion tests with various $\mathrm{pH}$ values: (a) $\mathrm{pH} 8.3$, (b) $\mathrm{pH} 9.3$, (c) $\mathrm{pH} 9.8$, (d) $\mathrm{pH} 11.1$, and (e) $\mathrm{pH} 12.4$

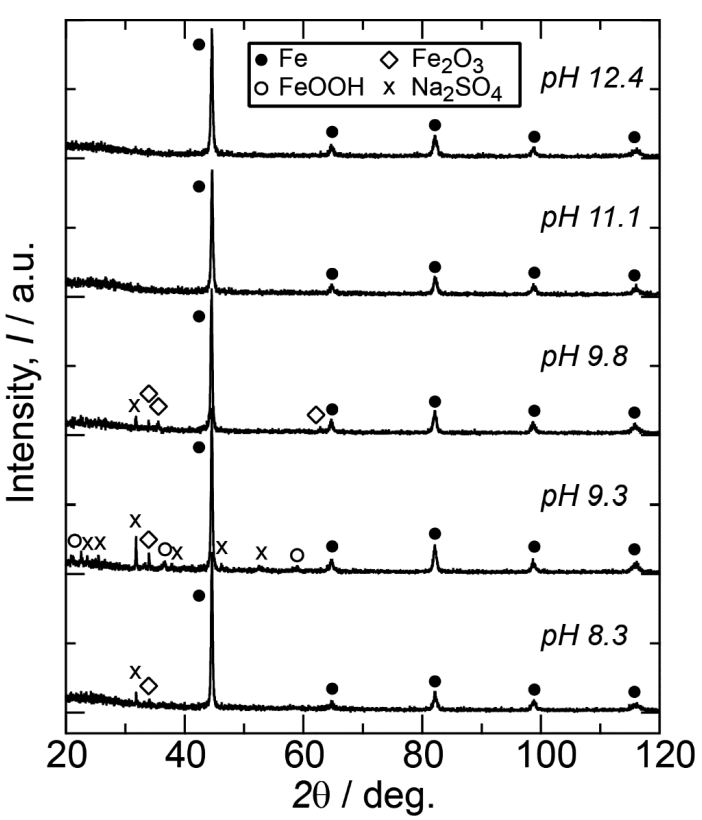

Fig. 4 XRD patterns for the surfaces of the steel disks measured after 24-h immersion tests in various $\mathrm{pH}$ solutions.

sity due to the reduction of dissolved oxygen was observed; the current increased with cathodic polarization, due to the hydrogen evolution reaction. In contrast, in the case of a $\mathrm{pH}$ lower than 9.3, a limiting current density was not clearly visible. The difference between these cathodic polarization behaviors at different $\mathrm{pH}$ values is due to the difference in the magnitude of anodic polarization behavior around the corrosion potential. Figure 5 shows a Tafel plot of the anodic cur- 
rent density for the steel disks in the test solutions with $\mathrm{pHs}$ of 8.3 and 9.3; the current density increased linearly with the anodic polarization from the corrosion potential. Therefore, the corrosion potential shifts in the less noble direction with decreasing test solution $\mathrm{pH}$, and the diffusion limiting current region can be hindered with a high anodic current around the corrosion potential.

From the results of the polarization measurements, polarization resistance for steel disks in the test solutions, which can be an index of corrosion rate, was calculated using the current-potential relationship around the corrosion potential. Figure 7 shows changes in the polarization resistance of the

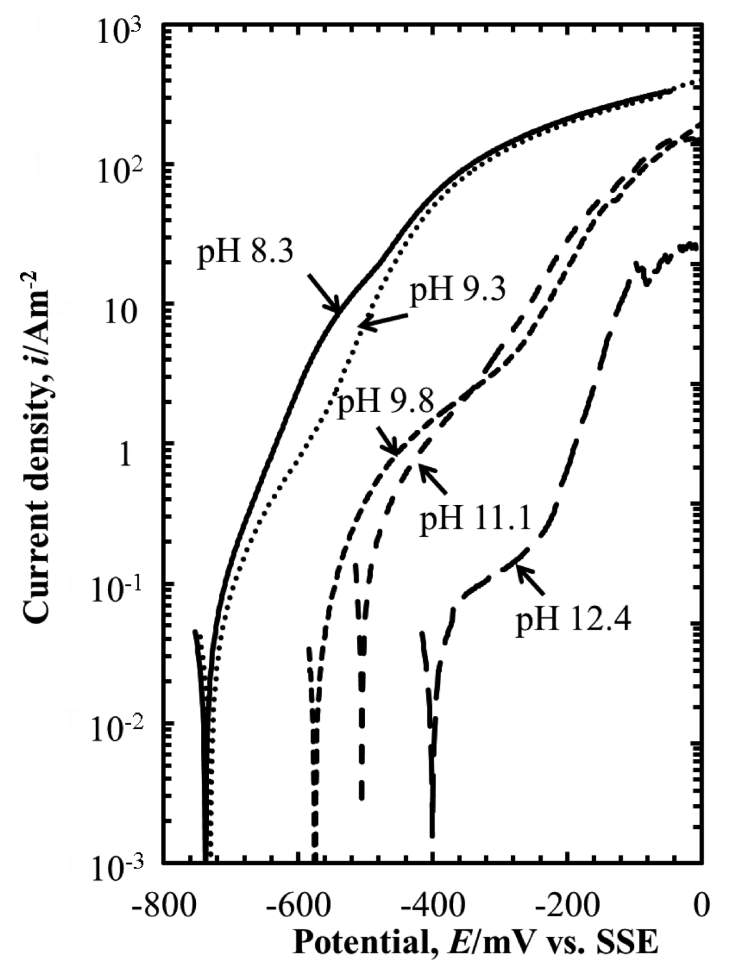

Fig. 5 Anodic polarization curves for the steel disks measured in the test solutions with various $\mathrm{pH}$ values. steel disks as a function of solution $\mathrm{pH}$. Polarization resistances in the $\mathrm{pH}$ region below 11.1 increased slightly with $\mathrm{pH}$ (Fig. 7); however, the resistance increased dramatically at $\mathrm{pH}$ 12.4. These results suggest that the corrosion rate slows with increasing $\mathrm{pH}$ and that, in addition, at $\mathrm{pH} 12.4$, the corrosion rate is quite low due to the passive state on the surface of the steel disks. These results are in good agreement with the surface morphology and electrochemical behavior shown in Figs. 5 and 6.

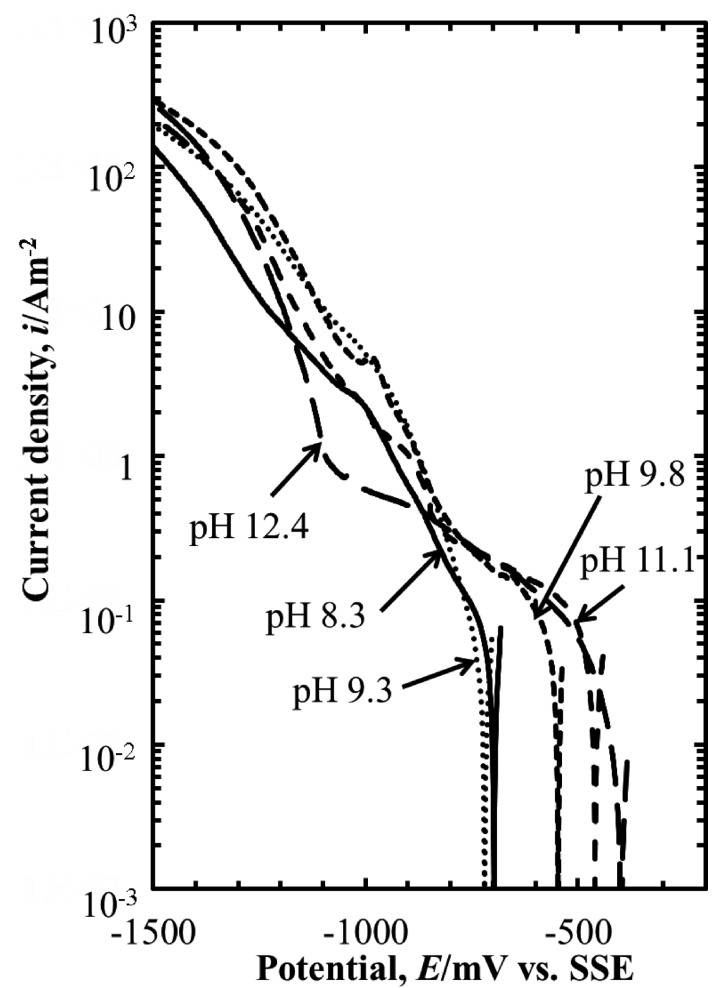

Fig. 6 Cathodic polarization curves for the steel disks measured in the test solutions with various $\mathrm{pH}$ values.

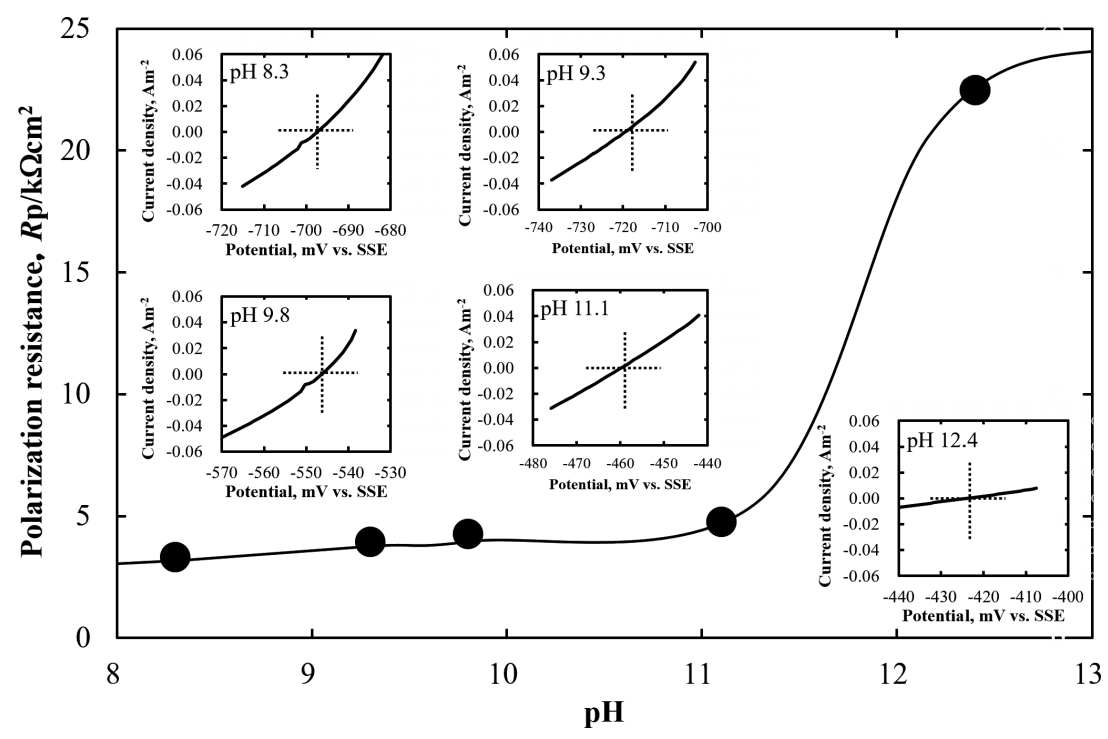

Fig. 7 Change in the polarization resistance of the steel disks as a function of solution $\mathrm{pH}$. 


\subsection{Influence of $\mathrm{pH}$ on hydrogen absorption into steel}

Figure 8 shows the TDA spectra for steel disks measured after immersion over a range of durations in the $\mathrm{pH} 8.3$ test solution. The TDA spectrum labelled "Blank" was obtained without an immersion test. All spectra in Fig. 8 show that the peak hydrogen desorption rate is observed at almost the same temperature, meaning that the trapping state of absorbed hydrogen is nearly identical, regardless of immersion. Hydrogen atoms that are desorbed from the steel disks at room temperature are considered to be weakly trapped, so-called diffusible hydrogen ${ }^{10)}$.

Furthermore, as shown in Fig. 8, the peak heights of the hydrogen desorption rate increased steadily with immersion duration; thus, the amount of absorbed hydrogen increases with progressing steel corrosion. The TDA results indicated that hydrogen atoms evolve during steel corrosion and are absorbed by the steel disks in the $\mathrm{pH} 8.3$ test solution.

The amount of absorbed hydrogen can be calculated by integrating the hydrogen desorption rate along the temperature axis from $30^{\circ} \mathrm{C}$ to $200^{\circ} \mathrm{C}$, because the temperature axis can be converted to time using the constant heating rate of $200^{\circ} \mathrm{C} / \mathrm{h}$. However, at this time, it is needed to take account of residual amount of absorbed hydrogen in steel disk before immersion tests. This is because the desorption of hydrogen atoms was detected on steel disks without an immersion test as observed in the spectrum labelled "Blank" in Fig. 8. The absorbed hydrogen in the steel disk before immersion test can be attributed to hydrogen evolution reaction occurring with steel corrosion during sample preparation such as slicing or polishing in

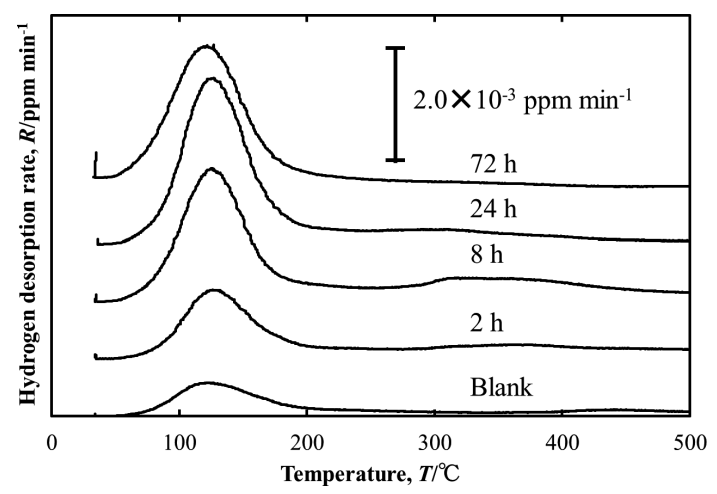

Fig. 8 TDA spectra for steel disks measured after immersion over a range of durations in the $\mathrm{pH} 8.3$ test solution.

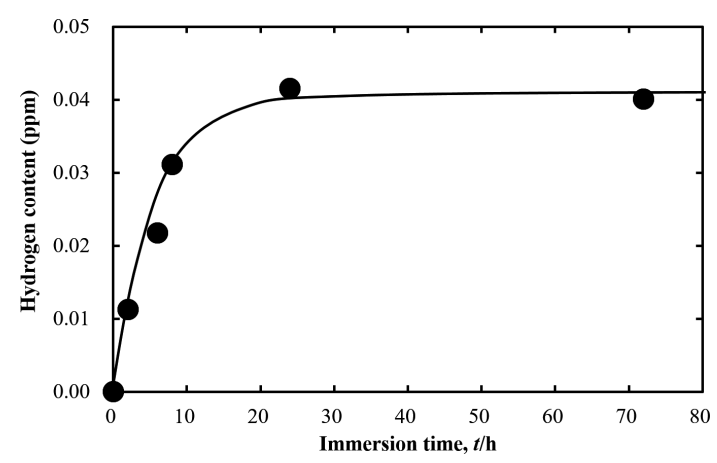

Fig. 9 Change in hydrogen content in the steel disks as a function of immersion time in the $\mathrm{pH} 8.3$ test solution. aqueous media. In fact, hydrogen atom desorption was not detected from the steel disk that had been left in ambient environment for one week after sample preparation, because diffusible hydrogen was desorbed from the disks. Therefore, the residual amount of absorbed hydrogen calculated from the "Blank" TDA spectrum was subtracted from the calculated amount of absorbed hydrogen during the immersion tests.

Figure 9 shows the amount of absorbed hydrogen in the steel disks (the hydrogen content) as a function of immersion time in the $\mathrm{pH} 8.3$ test solution. The hydrogen content increased rapidly with immersion time and saturated within $24 \mathrm{~h}$.

Figure 10 shows TDA spectra for the steel disks after 24-h immersion tests in test solutions over a range of $\mathrm{pH}$ values. The desorption of hydrogen atoms from the steel disks was detected for all $\mathrm{pH}$ cases, although for $\mathrm{pHs} 9.8$ and 11.1, the peaks in the TDA spectra were small and nearly identical to the peak in the "Blank" spectrum (Fig. 10). This indicates that hydrogen atoms may not be absorbed during the immersion tests at pHs 9.8 and 11.1. Hydrogen atoms are absorbed into steel disks when the $\mathrm{pH}$ is less than 9.3.

Figure 11 shows the hydrogen content absorbed into the steel disks after 24-h immersion tests as a function of the $\mathrm{pH}$ of the test solutions. The hydrogen contents were also calculated using the same procedure as described before. The hydrogen contents for test solutions of $\mathrm{pH}$ greater than 9.8 were the same as for the "Blank" case; that is, few hydrogen atoms

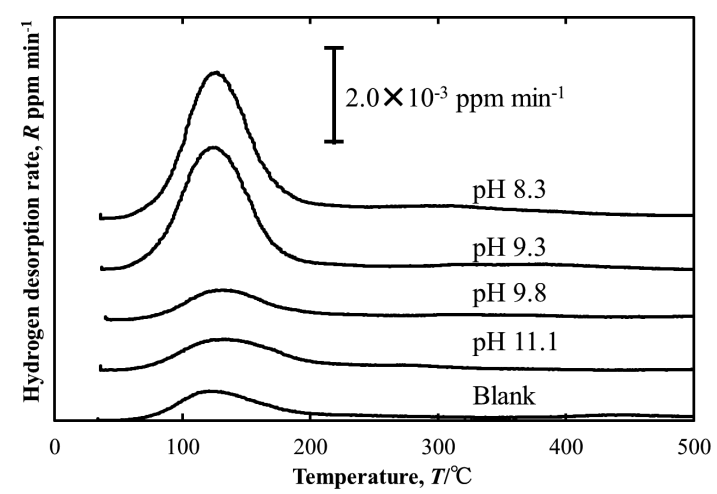

Fig. 10 TDA spectra for the steel disks measured after 24-h immersion tests in test solutions over a range of $\mathrm{pH}$ values.

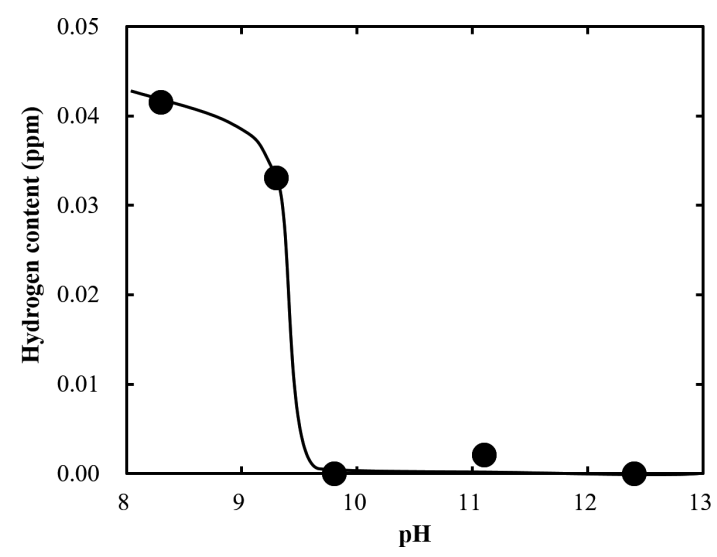

Fig. 11 Change in hydrogen content absorbed into the steel disks after 24-h immersion tests as a function of the $\mathrm{pH}$ of the test solutions. 
were absorbed into the steel disks during immersion in a $\mathrm{pH}$ over 9.8. In contrast, as shown in Fig. 11, the amount of absorbed hydrogen increased with decreasing $\mathrm{pH}$ below 9.3, indicating that hydrogen atoms are absorbed at $\mathrm{pH}$ values lower than 9.3.

\section{Discussion}

\subsection{Steel corrosion in neutral and weak alkaline solu- tions}

The corrosion potentials of steel disks decrease significantly between $\mathrm{pH} 9.8$ and pH 9.3 (Fig. 2). In addition, from corrosion morphology results, iron corrosion products clearly precipitated on the steel surfaces in test solutions with a $\mathrm{pH}$ less than 9.8. These results suggest that corrosion reactions taking place on steel surfaces change drastically at around neutral $\mathrm{pH}$. These results coincide with those by Heut et al., who reported a transition from passive to active corrosion of steel in carbonated concrete at $\mathrm{pH}$ between 9.4 and $10^{11)}$.

Similarly, as reported by Davies et al., carbon steel forms a pseudo-passive $\mathrm{Fe}(\mathrm{OH})_{2}$ and/or $\mathrm{FeCO}_{3}$ layer during anodic polarization in bicarbonate solution through the following reactions $^{12,13)}$ :

$$
\begin{gathered}
\mathrm{Fe}+2 \mathrm{H}_{2} \mathrm{O} \rightarrow \mathrm{Fe}(\mathrm{OH})_{2}+2 \mathrm{H}^{+}+2 \mathrm{e}^{-} \\
\mathrm{Fe}+\mathrm{HCO}_{3}^{-} \rightarrow \mathrm{FeCO}_{3}+\mathrm{H}^{+}+2 \mathrm{e}^{-}
\end{gathered}
$$

According to Moreno et al., the pseudo-passive layer is confirmed to play no role in preventing steel corrosion ${ }^{14)}$.

In this study, the fully passive state was observed at $\mathrm{pH}$ 12.4. On the other hand, although some parts of the surfaces retained metallic luster, small amount of corrosion products were observed on the steel disk tested at 11.1, as shown in Fig. 3. In addition, from the results of XRD measurements (Fig. 4), corrosion products of $\mathrm{FeOOH}$ and $\mathrm{Fe}_{2} \mathrm{O}_{3}$ were detected on steel after immersion in solutions with a $\mathrm{pH}$ less than 9.8. Thus, the passive state is broken at $\mathrm{pH} 11.1$, leaving a pseudo-passive state. Further, with decreasing $\mathrm{pH}$ to neutral values, the dissolution of $\mathrm{FeCO}_{3}$, shown in eq. (6) ${ }^{2)}$, takes place due to enhancement of the anodic reaction.

$$
\mathrm{FeCO}_{3}(\mathrm{aq})+2 \mathrm{H}_{2} \mathrm{O} \leftrightarrow \mathrm{FeOOH}+2 \mathrm{H}^{+}+\mathrm{e}^{-}+\mathrm{HCO}_{3}^{-}
$$

The transition of the surface state from passive to active can be considered to occur on steels at $\mathrm{pH}$ between 9.3 and 9.8 , resulting in enhancement of steel corrosion.

\subsection{Hydrogen absorption into steel in neutral and weak alkaline solutions}

In alkaline environments such as fresh concrete structures, the cathodic reaction taking place on steel is mainly the reduction reaction of dissolved oxygen ${ }^{2)}$. However, in the case of neutral environments such as aging concretes, simultaneous reduction of hydrogen ions can also take place to form adsorbed hydrogen atoms on the steel surface. Furthermore, the adsorbed hydrogen atoms can be partially absorbed into the steel. Proverbio et al. reported that, even at $\mathrm{pH} 8.3$, the hydrogen evolution reaction occurs on the steel surface with a potential lower than $-730 \mathrm{mV}$ vs. SCE, a calomel reference electrode in saturated $\mathrm{KCl}^{15}$.

The relationship between the hydrogen content and the corrosion potential of steel disks in test solutions with a range of $\mathrm{pH}$ values is shown in Fig. 12. The hydrogen content increased dramatically when the corrosion potential was less than $-600 \mathrm{mV}$ vs. SSE. This result suggests that adsorption of hydrogen atoms occurs in test solutions of $\mathrm{pHs} 8.3$ and 9.3 due to the reduction reaction of water. The slight decrease in the charge transfer resistance in the test solutions with $\mathrm{pHs}$ lower than 9.8 suggests that hydrogen ions can be reduced simultaneously. This result is also in good agreement with the polarization behaviors shown in Figs. 5 and 6. Therefore, hydrogen atoms are absorbed in steel due to a decrease in the corrosion potential.

To investigate whether hydrogen evolution can occur thermodynamically during the immersion tests, corrosion potentials measured after 24-h immersion were plotted in a $\mathrm{pH}$-potential diagram for iron at $25^{\circ} \mathrm{C}$ in the aqueous solutions containing carbonates (Fig. 13). In this diagram, the total concentrations of iron and carbonate species were maintained at molarities of $1 \times 10^{-6} \mathrm{~mol} / \mathrm{kg}$ and $50 \mathrm{mmol} / \mathrm{kg}$, respectively. The corrosion potentials in the solution at $\mathrm{pH} 9.3$ were nearly on the equilibrium line for hydrogen evolution. In addition, the corrosion potential is less noble than the line at $\mathrm{pH} 8.3$. These results support the conclusion that hydrogen evolution takes place on steel disks during immersion in test solutions with a $\mathrm{pH}$ of less than 9.3 .

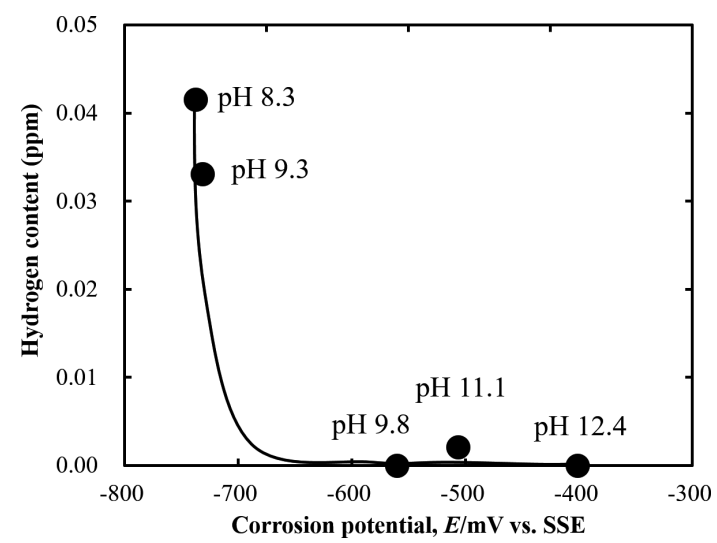

Fig. 12 Relationship between the hydrogen content and the corrosion potential of steel disks in test solutions with a range of $\mathrm{pH}$ values.

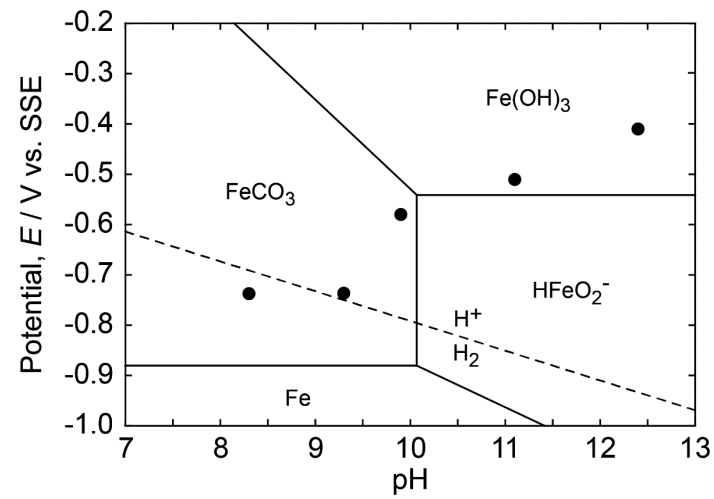

Fig. 13 Potential-pH diagram for iron in neutral and alkaline solutions containing $\mathrm{CO}_{3}{ }^{2-}$ ions. 


\subsection{Hydrogen absorption into steel in aging concretes}

The process of hydrogen absorption into steel in neutral and weak alkaline solutions simulating pore water in aging concretes can be summarized as follows. At the beginning of the exposure of fresh concretes to atmospheric corrosion environments, steels are in high-alkaline pore water. Under these conditions, the steels are in a passive state and maintain higher corrosion potentials than the line of hydrogen evolution, resulting in no hydrogen atom absorption into steels. However, as the $\mathrm{pH}$ in the pore water decreases due to aging and neutralization, the surface state of the steels changes from the passive to the pseudo-passive or active state. This transition can enhance steel corrosion, such that corrosion potentials shift to less noble ones. However, few hydrogen atoms are absorbed into the steel due to the high corrosion potential, which is maintained by the formation of a pseudo-passive film. Then, as concrete is carbonated further, the anodic reaction transitions occur from the formation of a pseudo-passive film to iron dissolution. The corrosion potential decreases at $\mathrm{pH}$ values below $\mathrm{pH} 9.3$ due to anode reaction acceleration. As a result, the corrosion potential decreases significantly and hydrogen is absorbed into the steel.

As summarized by Matsuyama, the susceptibility to hydrogen embrittlement of high-strength steels is mainly associated with their strength ${ }^{16)}$. In this study, 1420-MPa-class steels were used as the test material. According to the schematic drawing of the relationship between the susceptibility for hydrogen embrittlement and the strength of steels, a concentration of diffusible hydrogen atoms at the sub-ppm level can be considered to have potential for hydrogen embrittlement for $1500-\mathrm{MPa}$-class steels. Although the hydrogen content evaluated at $\mathrm{pH} 8.3$ is one-order lower than the sub-ppm level, as shown in Fig. 12, the hydrogen content can increase locally at defects in the steel, such as vacancies and dislocations ${ }^{17,18)}$. Therefore, to investigate further whether hydrogen embrittlement can occur in aging concretes, the mechanical properties of steel after immersion tests in neutral solutions should be evaluated.

\section{Conclusions}

Hydrogen absorption behavior into steel was investigated using corrosion and electrochemical measurements and thermal desorption analysis in neutral and weak alkaline solutions simulating pore waters in aging concrete. The findings were as follows:

(1) From the results of the immersion tests on steel disks in neutral and alkaline solutions, corrosion potentials decrease in the less noble direction with decreasing $\mathrm{pH}$ from alkaline to neutral. Furthermore, the corrosion potentials drop dramatically towards the less noble direction at around $\mathrm{pH} 9.3$.

(2) The charge transfer resistance of the steel disks in the test solutions maintains a relatively high value at $\mathrm{pH}$ 12.4 and decreases with decreasing $\mathrm{pH}$. These results indicate that in solutions of $\mathrm{pH}$ greater than 12.4, the steel surfaces maintained a passive state; however, in solutions with a $\mathrm{pH}$ lower than 11.1 , the passive film broke down and active dissolution of the steel was enhanced with decreasing $\mathrm{pH}$.

(3) From the TDA spectra results, although absorption of hydrogen atoms into steel disks was not clearly detected in the $\mathrm{pH}$ region over 9.8, the absorption of hydrogen atoms was clearly confirmed in test solutions with a $\mathrm{pH}$ below 9.3. The amount of absorbed hydrogen increased in neutral solutions with decreasing $\mathrm{pH}$. These results suggest that hydrogen atoms can form on steel surfaces during corrosion in neutral solutions.

\section{REFERENCES}

1) M.A. Climent and C. Gutiérrez: Surf. Sci. 330 (1995) L651-L656.

2) B. Huet, V. L'Hostis, F. Miserque and H. Idrissi: Electrochim. Acta 51 (2005) 172-180.

3) P. Dangla and W. Dridi: Corros. Sci. 51 (2009) 1747-1756.

4) M. Perrin, L. Gaillet, C. Tessier and H. Idrissi: Corros. Sci. 52 (2010) 1915-1926.

5) L. Vehovar, V. Kuhar and A. Vehovar: Eng. Fail. Anal. 5 (1998) 21-27.

6) M. Ichiba, J. Sakai, T. Doshida and K. Takai: Scr. Mater. 102 (2015) 59-62.

7) T. Hara and T. Tarui: Zairyo-to-Kankyo 59 (2010) 173-178.

8) J. Toribio and E. Ovejero: Eng. Fail. Anal. 12 (2005) 654-661.

9) J. Sanchez, S.F. Lee, M.A. Martin-Rengel, J. Fullea, C. Andrade and J. Ruiz-Hervias: Eng. Fail. Anal. 59 (2016) 467-477.

10) L. Cheng, M. Enomoto, D. Hirakami, and T. Tarui: ISIJ Inter. 53 (2013) 131-138.

11) B. Huet, V. L'hostis, G. Santarini, D. Feron and H. Idrissi: Corros. Sci. 49 (2007) 1918-1932.

12) D.H. Davies and G.T. Burstein: Corrosion 36 (1980) 416-422.

13) X. Mao, X. Li, R. and W. Revie: Corrosion 50 (1994) 651-657.

14) M. Moreno, W. Morris, M.G. Alvarez and G.S. Duffo: Corros. Sci. 46 (2004) 2681-2699.

15) E. Proverbio and P. Longo: Corros. Sci. 45 (2003) 2017-2030.

16) S. Matsuyama: Okurehakai, (Nikkan kogyo shinbun, Japan, 1989) pp. $68-74$

17) T. Doshida and K. Takai: Acta Mater. 79 (2014) 93-107.

18) M. Wang, E. Akiyama and K. Tsuzaki: Corros. Sci. 48 (2006) 21892202 . 